\title{
A retrospective analysis of the use of loteprednol etabonate ophthalmic suspension $0.5 \%$ following canaloplasty
}

This article was published in the following Dove Press journal:

Clinical Ophthalmology

\author{
Mahmoud A Khaimi \\ Dean McGee Eye Institute, Oklahoma \\ City, OK, USA
}

Background: While loteprednol etabonate (LE) suspension $0.5 \%$ is approved for the treatment of postoperative ocular inflammation, there have been no reported studies of its use in glaucoma patients undergoing canaloplasty.

Methods: This was a retrospective medical chart review conducted at a single US center. Data were collected on patients with glaucoma who underwent canaloplasty with or without cataract surgery, and were prescribed LE suspension $0.5 \%$ postoperatively. Outcomes evaluated included postsurgical inflammation (anterior chamber [AC] cells and flare), intraocular pressure (IOP), number of IOP-lowering medications, and postsurgical complications.

Results: Data were collected on 204 patients (262 eyes) with a mean (SD) age of 71.6 (11.3) years. The most frequent LE dosing regimens at day 1 , week 1 , and month 1 postsurgery were QID (92.3\%; 241/261), TID (52.6\%; 133/253), and QD (65.5\%; 78/119), respectively. Inflammation (AC flare and cells), mostly mild, was noted in $33.2 \%(86 / 259)$ of eyes on postoperative day 1 and 8.6\% (21/244) of eyes at month 1. Mean IOP and mean number of IOP-lowering medications were significantly reduced from baseline $(P<0.001)$ at all time points postoperatively. Complete (no IOP-lowering medication) or qualified (use of $\leq 2$ IOP-lowering medications) surgical success was achieved in $78.8 \%$ and $90.6 \%$ of eyes, respectively, at month 6 and $63.4 \%$ and $92.7 \%$ of eyes at month 36 . The most frequently observed postoperative complication was hyphema in $48.7 \%$ (126/259) eyes at day 1 , which decreased to $0.4 \%(1 / 244)$ of eyes by month 1 . IOP $\geq 30 \mathrm{mmHg}$ was noted in 13 (5.3\%) eyes at postoperative week 1 and rarely thereafter, and no patient discontinued therapy because of an IOP increase.

Conclusion: These real-world data suggest that canaloplasty with or without cataract surgery managed postoperatively with LE suspension $0.5 \%$ is effective and safe in the glaucoma patient.

Keywords: canaloplasty, loteprednol etabonate, postoperative inflammation, glaucoma, intraocular pressure

\section{Introduction}

Intraocular pressure (IOP) lowering is a proven treatment strategy that slows progression of glaucomatous optic nerve injury and visual field loss in patients with glaucoma. ${ }^{1-7}$ Initial strategies for IOP lowering include use of medications and laser trabeculoplasty. ${ }^{8,9}$ However, if these approaches fail to adequately control IOP, incisional glaucoma surgery is usually required..$^{4,8,9}$ The traditional surgical technique for lowering IOP is trabeculectomy, which increases aqueous humor outflow through a partial removal of the trabecular meshwork/Schlemm's canal and the creation of a subconjunctival filtering bleb. ${ }^{10,11}$ However, this procedure may be associated with
Correspondence: Mahmoud A Khaim Dean McGee Eye Institute, 608 Stanton L Young Blvd, Oklahoma City, OK 73I0, USA Email mahmoud-khaimi@dmei.org 
complications, including bleb infections, choroidal detachment, and scarring of the conjunctival tissue leading to failure of the bleb. ${ }^{8,12-15}$

Canaloplasty is a minimally invasive, nonpenetrating surgical technique that lowers IOP by restoring, rather than partially removing, the trabecular meshwork/Schlemm's canal. ${ }^{16-21}$ As the procedure does not create a permanent fistula in the eye wall, the likelihood of postsurgical complications is reduced, and patient follow-up is simplified relative to trabeculectomy. ${ }^{15,22-26}$ Canaloplasty enhances natural transtrabecular outflow over the long term by tensioning of the meshwork and opening of the trabecular plates, viscodilation of the Schlemm's canal, and the creation of a scleral lake and Descemet's window. ${ }^{27,28}$ Performing the procedure without a tensioning suture spares conjunctival manipulation for possible future procedures and is termed ab-interno canaloplasty. ${ }^{29}$ In follow-up studies of glaucoma patients who underwent canaloplasty, IOP reduction was maintained as long as 4 years, with a significant decline in the need for medication and/or additional surgical treatment. ${ }^{17,18,20,26,30-32}$ Canaloplasty can be performed in conjunction with cataract surgery with reported improved outcomes over cataract surgery alone in the majority of studies. ${ }^{16,21,24,28,30,31,33}$

Postoperative management following canaloplasty typically involves topical antibiotics for 1 week and topical corticosteroids tapered over 3-4 weeks. $^{29,34}$ Although routinely used for reducing postsurgical inflammation and improving patient comfort following ocular surgery, corticosteroid use can be associated with a number of potential adverse effects of particular concern to the glaucoma patient, such as steroid-induced IOP increases, decreased wound healing, and cataract formation in phakic eyes. ${ }^{35-40}$

Loteprednol etabonate (LE) is a topical ophthalmic corticosteroid that contains a chloro-methyl ester group at the carbon 20 position instead of the ketone group present in other corticosteroids. This unique structure facilitates rapid metabolism of LE molecules that are unbound to glucocorticoid receptors into inactive metabolites, ${ }^{41-44}$ allowing LE to exert the desired anti-inflammatory activity while reducing the likelihood of unwanted effects. ${ }^{41,43,45,46}$ LE ophthalmic suspension 0.5\% (Lotemax $^{\circledR}$ suspension; Bausch + Lomb, Bridgewater, NJ, USA) was approved in 1998 for the treatment of postoperative inflammation following ocular surgery, in addition to steroid-responsive inflammatory conditions such as seasonal allergic conjunctivitis and uveitis.

Multiple studies have demonstrated the anti-inflammatory efficacy and safety (including minimal effect on IOP) of LE suspension $0.5 \%$ used postsurgically in patients undergoing cataract surgery, photorefractive keratectomy, and laserassisted in situ keratomileusis. ${ }^{47-52}$ Further studies have demonstrated that LE suspension has a low propensity to elevate IOP, ${ }^{53}$ including in known corticosteroid responders ${ }^{54,55}$ and in comparison with other corticosteroids. ${ }^{56-61}$

To date, two retrospective chart reviews have evaluated the use of LE suspension $0.5 \%$ in patients undergoing glaucoma surgery. ${ }^{62,63}$ Patients treated with LE $0.5 \%$ experienced a minimal effect on IOP and a significant reduction in the number of glaucoma medications needed following combined phacoemulsification and trabecular microbypass stent implantation. ${ }^{62}$ Similarly, there was no difference in IOP in patients undergoing selective laser trabeculoplasty who received LE $0.5 \%$ at the time of surgery compared to those not receiving corticosteroid. ${ }^{63}$ However, the effect of LE on inflammation was not reported in these studies, and, to date, there are no published data addressing outcomes with the use of LE in patients following canaloplasty. This retrospective study evaluated postsurgical success and safety outcomes, including IOP findings, in patients managed with LE $0.5 \%$ suspension postoperatively after canaloplasty with or without phacoemulsification and intraocular lens (IOL) implantation.

\section{Methods \\ Study design}

This retrospective chart review was conducted at a single center (Dean McGee Eye Institute, University of Oklahoma, Oklahoma City, OK, USA). Retrospective data were collected on the routine care and follow-up of patients who underwent canaloplasty with or without simultaneous phacoemulsification and IOL implantation between January 19, 2010, and March 5, 2013, for whom LE suspension 0.5\% was prescribed as part of postoperative management. All patient data were de-identified and kept confidential, as specified by the International Conference on Harmonization Guidelines for Good Clinical Practice. ${ }^{64}$ The Institutional Review Board at the University of Oklahoma approved the protocol and waived the need for informed consent, given that all patient data were de-identified for the purposes of the study.

Eligible patients were $\geq 18$ years of age with a diagnosis of glaucoma who underwent canaloplasty (either with or without simultaneous phacoemulsification and IOL implantation) and were treated postoperatively with LE suspension $0.5 \%$. Exclusion criteria included use of a topical corticosteroid other than LE during the preoperative evaluation period and/or within 1 day of the postoperative period. If an included eye had documented the use of another topical corticosteroid at any of the subsequent follow-up visits, 
data from that eye were included only up to the time of receipt of the non-LE corticosteroid.

\section{Surgical procedures}

The details of the canaloplasty procedure have been described previously. ${ }^{16-18,20,26,27,29,30,34,65}$ For the cases included in this chart review, one surgeon (MK) performed all canaloplasty procedures according to the same standard of care. Surgical preparation included a peribulbar or retrobulbar block followed by conjunctival and subsequent superficial flap dissection. For those patients undergoing a combined procedure including phacoemulsification and IOL implantation, a temporal clear corneal incision and posterior chamber IOL implantation were performed before dissection of the deep flap creating a Descemet window.

Schlemm's canal was unroofed through the surgical creation and removal of a deep scleral flap. A microcatheter (iTRACK-250; Ellex) was inserted and guided through this opening for the entire $360^{\circ}$ of Schlemm's canal. Before reversing and removing the catheter from Schlemm's canal, those eyes undergoing the ab-externo approach had a stent suture tied under tension at the catheter's distal tip to maintain inward distention of the trabecular meshwork. If there was failure to completely catheterize the eye, no suture was tied. Postoperative management, initiated 1 day postsurgery, included third- or fourth-generation fluoroquinolone drops TID or QID for 2 weeks and LE suspension $0.5 \%$ QID for 1 week and tapered over the next 3-4 weeks.

\section{Data collected and reported outcomes}

Data were collected for the presurgical visit (baseline) and all postsurgical visits starting on day 1 (the day after surgery) and extending to the longest available follow-up visit up to a maximum of 3 years. Data extracted from patient charts included the following: patient demographics; surgical characteristics; LE suspension dosing, frequency, and duration; ocular inflammation (anterior chamber [AC] cells and flare); IOP (by Goldmann applanation tonometry); concomitant medications; visual acuity (VA; Snellen); and adverse events (AEs). Inflammation (AC cells and AC flare data) was scored using a 6-point severity scale $(0,0.5,1,2,3,4$, or unknown [inflammation present using terms such as rare or occasional, but no grade]). Hyphema was scored according to the presence of red blood cells in the AC using a 6 -grade scale (none, micro [trace], grade I $[\leq 33 \%$ filling of the AC], grade II [ $33 \%-50 \%$ filling of the AC], grade III [ $>50 \%-<100 \%$ filling of the AC], grade IV [100\% filling of the $\mathrm{AC}]$, or unknown).
Outcomes evaluated included mean postsurgical inflammation (AC cells and flare), IOP, VA, number of concomitant IOP-lowering medications, postsurgical complications (injection and hyphema), and AEs.

\section{Data analysis}

Eyes of patients in which both eyes qualified for inclusion were treated independently for all outcomes. Where data for IOP and/or VA were available, a lack of recorded data for outcomes other than IOP and VA was imputed as "zero" or "none". When neither IOP nor VA was recorded, a lack of recorded data for other outcomes was imputed as missing. Data for hyphema and inflammation were not collected past postoperative month 3 .

When calculating the number of glaucoma medications at follow-up visits, combination medications were counted as two medications. The percentage of eyes achieving postoperative IOPs of $\leq 21, \leq 18$, and $\leq 15 \mathrm{mmHg}$ without use of IOP-lowering medications at the postoperative time points of 6 months, 12 months, 18 months, 2 years, and 3 years were calculated. Canaloplasty surgery was deemed a complete success if eyes attained target IOP without the use of IOP-lowering medications. Qualified success was defined similarly, but with adjunctive use of $\leq 2$ IOP-lowering medications.

Postoperative inflammation was reported as the percentage of eyes with any noted inflammation (AC cells and/or AC flare) and the percentage of eyes graded by severity of inflammation in terms of AC cells and AC flare. Hyphema findings were reported as the percentage of eyes with any observed hyphema and the percentage of eyes by severity grade. VA was converted from Snellen to logarithm of the minimum angle of resolution or logMAR.

The number of IOP-lowering medications and IOP (analyzed as change from baseline) at each time point postsurgery was compared to baseline using a paired $t$-test (Statistical Analysis Software Version 7; SAS Institute). Statistical significance was defined as $P<0.05$. All other outcomes were analyzed descriptively.

\section{Results}

Data were collected on 204 patients (262 eyes) with a mean (SD) age of 71.6 (11.3) years, mostly Caucasian (70.3\%), and evenly divided between men and women (Table 1). Fiftyeight $(28.4 \%)$ patients had surgery performed in both eyes on separate days. Primary open-angle glaucoma (POAG) with or without nuclear sclerotic cataract was the most frequent diagnosis at the time of surgery $(91.8 \%$ of eyes) (Table 1$)$. 
Table I Baseline and surgical characteristics of study subjects and eyes

\begin{tabular}{|c|c|}
\hline Subjects & $\begin{array}{l}\text { Subjects n (\%) } \\
n=204\end{array}$ \\
\hline Age, mean, years (SD) & $71.6(11.3)$ \\
\hline Range & $18-93$ \\
\hline \multicolumn{2}{|l|}{ Sex, n (\%) } \\
\hline Male & $97(47.5)$ \\
\hline Female & $107(52.5)$ \\
\hline \multicolumn{2}{|l|}{ Race, n (\%) } \\
\hline Caucasian & $137(70.3)$ \\
\hline African American & $34(17.4)$ \\
\hline Native American & $17(8.7)$ \\
\hline Hispanic & $6(3.1)$ \\
\hline Asian & $\mathrm{I}(0.5)$ \\
\hline \multicolumn{2}{|l|}{ Surgical eye, n (\%) } \\
\hline OD only & $83(40.7)$ \\
\hline OS only & $63(30.9)$ \\
\hline OU & $58(28.4)$ \\
\hline \multirow[t]{2}{*}{$\overline{\text { Eyes }^{a}}$} & Eyes n (\%) \\
\hline & $n=262$ \\
\hline \multicolumn{2}{|l|}{ Glaucoma diagnosis $^{\mathrm{b}}$} \\
\hline POAG & $128(49.8)$ \\
\hline POAG, NSC & $108(42.0)$ \\
\hline PXG, NSC & $8(3.1)$ \\
\hline PXG & $4(1.6)$ \\
\hline Pigmentary glaucoma & $2(0.8)$ \\
\hline Ocular hypertension & $2(0.8)$ \\
\hline Other & $5(1.9)$ \\
\hline \multicolumn{2}{|l|}{ Suture tension, ${ }^{\mathrm{d}} \mathrm{n}(\%)$} \\
\hline Yes & $236(90.8)$ \\
\hline No & $24(9.2)$ \\
\hline \multicolumn{2}{|l|}{ Phaco IOL } \\
\hline Yes & $124(47.3)$ \\
\hline No & $138(52.7)$ \\
\hline
\end{tabular}

Notes: ${ }^{\mathrm{D}} \mathrm{Data}$ not available for all characteristics for all eyes. ${ }^{\mathrm{b}}$ Missing for five eyes. 'Other includes one case each of chronic angle-closure glaucoma with nuclear sclerotic cataract; inflammatory glaucoma; juvenile-onset open-angle glaucoma; mixed mechanism glaucoma with nuclear sclerotic cataract; pigmentary glaucoma with nuclear sclerotic cataract. Missing for 2 eyes.

Abbreviations: IOL, intraocular lens; NSC, nuclear sclerotic cataract; OD, right eye; OS, left eye; OU, both eyes; POAG, primary open-angle glaucoma; PXG, pseudoexfoliative glaucoma.

The majority of eyes (90.8\%) underwent canaloplasty with suture tensioning, and $47.3 \%$ of eyes underwent canaloplasty combined with phacoemulsification and IOL implantation. The total number of eyes available for analysis by visit was 262 at day 1, 255 at week 1, 244 at month 1, 210 at month 3,179 at month 6,164 at month 12,151 at month 18, 132 at month 24 , and 47 at month 36 . The primary reason eyes were not available for analysis at later visits was that patients could be sent back to their referral sources within 3-6 months following surgery. Other reasons included lack of a recorded outcome measure (eg, IOP) at a particular visit, discontinuation from the study because of the use of a steroid other than LE (further detail provided below), a missed visit, or being lost to follow-up.
Among included eyes, the first instillation of LE occurred at the postoperative day 1 visit, though one eye did not receive $L E$ until the postoperative week 1 visit. The majority of patients were prescribed LE for $<1$ month. The most frequent dosing regimen at day 1 , week 1 , and month 1 postsurgery was QID (92.3\%; 241/261), TID (52.6\%; 133/253), and QD $(65.5 \% ; 78 / 119)$ respectively (Table 2$)$. A total of 27 eyes $(10.3 \%)$ were switched to another corticosteroid at a time point after postoperative day 1 and were, therefore, excluded from analyses from that point onwards. In six eyes, this occurred within the first postoperative week, and in eight eyes, between 1 week and 1 month following surgery. Thereafter, between one and three eyes were discontinued for using a non-LE corticosteroid at each of the following postsurgery visits: month 3 , month 6 , month 12 , month 18 , year 2, and year 3. Patients were switched to another steroid primarily because after initially receiving a sample of LE, they were unable to pay for a follow-up LE prescription and/or LE was not covered by their health care insurance prescription plan.

There was no recorded use of antibiotics or nonsteroidal anti-inflammatory agents (NSAIDs) for included eyes prior to surgery (preoperative visit). Concomitant use of topical antibiotics at postoperative day 1 , week 1 , month 1 , and month 3 following surgery was reported in $100 \%(262 / 262)$, $67.4 \%(172 / 255), 4.9 \%(12 / 244)$, and $1 \%(2 / 210)$ eyes, respectively. Besifloxacin ophthalmic solution $0.6 \%$ (Besivance ${ }^{\circledR}$; Bausch + Lomb) was the most commonly utilized antibiotic and was administered TID in $60 \%$ eyes on postoperative day 1. Concomitant use of NSAIDs (bromfenac, ketorolac, or nepafenac) following surgery was reported in $27.8 \%(n=72 / 259), 20 \%(n=51 / 255), 2 \%(n=5 / 244)$, and $1 \%$ $(n=2 / 210)$ of eyes at these time points, respectively.

Table 2 Dosing frequency for LE suspension $0.5 \%$ over the first 3 month of postcanaloplasty

\begin{tabular}{|c|c|c|c|c|}
\hline \multirow[b]{2}{*}{ Time point } & \multicolumn{4}{|c|}{ Eyes receiving LE postoperatively (\%) } \\
\hline & $\begin{array}{l}\text { Day I } \\
(n=262) \\
n(\%)\end{array}$ & $\begin{array}{l}\text { Week I } \\
(n=255) \\
n(\%)\end{array}$ & $\begin{array}{l}\text { Month I } \\
(n=244) \\
n(\%)\end{array}$ & $\begin{array}{l}\text { Month } 3 \\
(n=210) \\
n(\%)\end{array}$ \\
\hline Total $^{a}$ & $26 I(99.6)$ & $253(99.2)$ & $119(48.8)$ & $2(1.4)$ \\
\hline \multicolumn{5}{|c|}{ Individual dosing frequencies ${ }^{\mathrm{b}}$} \\
\hline QD & $0(0)$ & $2(0.8)$ & $78(65.5)$ & $0(0)$ \\
\hline BID & $3(1.1)$ & $34(13.4)$ & $23(19.32)$ & $2(66.7)$ \\
\hline TID & $7(2.7)$ & $133(52.6)$ & II (9.24) & $0(0)$ \\
\hline QID & $24 \mid(92.3)$ & $79(31.2)$ & $6(5.04)$ & I (33.3) \\
\hline $6 \times /$ day & $9(3.4)$ & $5(2.0)$ & $0(0)$ & $0(0)$ \\
\hline Not specified & $\mathrm{I}(0.5)$ & $0(0)$ & $\mathrm{I}(0.8)$ & $0(0)$ \\
\hline
\end{tabular}

Notes: aTotal expressed as the percentage of all included eyes. ${ }^{\text {bDosing frequency }}$ expressed as percentage of total eyes that received LE.

Abbreviation: LE, loteprednol etabonate. 
Table 3 Inflammation grading for AC cells and AC flare by postoperative visit

\begin{tabular}{|c|c|c|c|c|c|c|c|}
\hline \multirow[t]{2}{*}{ Visit } & \multirow[t]{2}{*}{ Eyes, $n$} & \multicolumn{6}{|c|}{ AC cells or flare grade, $n(\%)$ eyes } \\
\hline & & 0 & 0.5 & 1 & 2 & 3 & 4 \\
\hline \multicolumn{8}{|l|}{ AC cells } \\
\hline Day I & 259 & $173(66.8)$ & $32(12.4)$ & $36(13.9)$ & $13(5.0)$ & $3(1.2)$ & $2(0.8)$ \\
\hline Week I ${ }^{\mathrm{a}}$ & 255 & $202(79.2)$ & $23(9.0)$ & $16(6.3)$ & $10(3.9)$ & $3(1.2)$ & 0 \\
\hline Month I & 244 & $223(9 \mid .4)$ & $10(4.1)$ & $8(3.3)$ & $3(1.2)$ & 0 & 0 \\
\hline Month 3 & 210 & $209(99.5)$ & 0 & 0 & $\mathrm{I}(0.5)$ & 0 & 0 \\
\hline \multicolumn{8}{|l|}{ AC flare } \\
\hline Day I & 259 & $234(90.4)$ & $2(0.8)$ & $22(8.5)$ & $\mathrm{I}(0.4)$ & 0 & 0 \\
\hline Week I & 255 & $233(91.4)$ & $8(3.1)$ & $12(4.7)$ & I (0.4) & I (0.4) & 0 \\
\hline Month I & 244 & $238(97.0)$ & I (0.4) & $5(2.1)$ & 0 & 0 & 0 \\
\hline Month 3 & 210 & 209 (99.5) & 0 & I (0.5) & 0 & 0 & 0 \\
\hline
\end{tabular}

Notes: a One eye graded as unknown at week I. Graded on a scale of 0, 0.5, I, 2, 3, or 4.

Abbreviation: AC, anterior chamber.

\section{Resolution of inflammation}

On postoperative day 1, 86 (33.2\%) eyes were noted to have some degree of inflammation (AC cells and/or flare) compared to $56(22.0 \%)$ eyes at week 1, $21(8.6 \%)$ eyes at month 1 , and $2(1.0 \%)$ eyes at month 3. Grading of AC cells and $\mathrm{AC}$ flare indicated that inflammation was mostly mild (grade of either 0.5 or 1 ) in severity (Table 3 ).

\section{Surgical outcomes}

Figure 1 shows mean IOP in included eyes before and following surgery. Mean IOP was significantly reduced from baseline $(P<0.001)$ at all postoperative time points. The mean preoperative (SD) IOP was 19.5 (6.6) $\mathrm{mmHg}$, with 21 eyes noted to have an IOP $\geq 30 \mathrm{mmHg}$. At postoperative day 1 , mean IOP decreased by $46.7 \%$ ( $P<0.001$ vs presurgery) and remained significantly lower compared with baseline at each subsequent follow-up visit through year 3 .
The mean (SD) number of IOP-lowering medications used per eye decreased significantly from 2.1 (1.22) presurgery to $0.0(0.9)$ at day $1,0.0(0.22)$ at week $1,0.1$ $(0.43)$ at month $1,0.1(0.51)$ at month 6 , and $0.6(0.83)$ at month $36(P<0.001$ at all postsurgical time points vs baseline) (Figure 2).

Mean (SD) VA in logMar prior to surgery was 0.32 (0.37). A worsening in VA from baseline was observed at the day 1 , week 1 , and month 1 postoperative visits, with values of $0.83(0.52), 0.56(0.42)$, and $0.39(0.34)$, respectively. However, for all subsequent visits, mean VA either appeared similar to baseline (month 3 and year 3) or improved over baseline (month 6 , month 12 , month 18 , and year 2).

Surgical success rates at IOP values of $\leq 21,18$, and $15 \mathrm{mmHg}$ are presented in Table 4. Among 170 eyes with data at 6 months follow-up, complete success (no use of IOP-lowering medication) was achieved in $78.8 \%$ of eyes

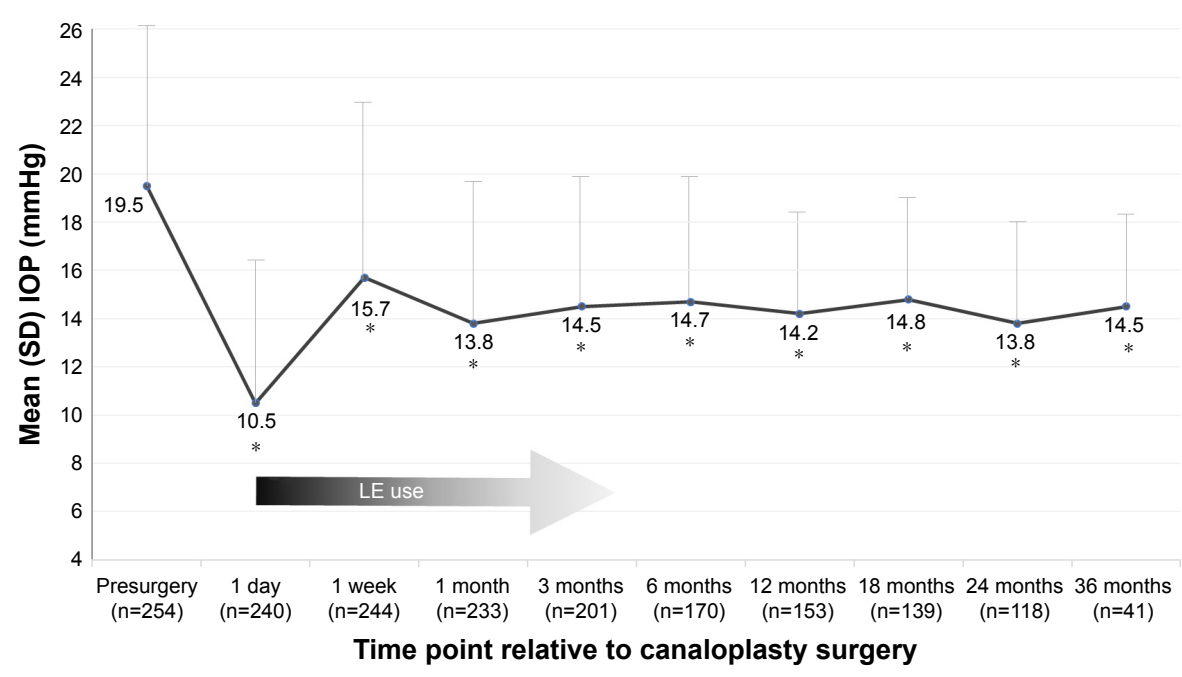

Figure I Mean intraocular pressure in eyes treated with LE suspension $0.5 \%$ postcanaloplasty.

Notes: $* P<0.001$ vs baseline. $n$, number of subjects with evaluable data at each time point.

Abbreviations: IOP, intraocular pressure; LE, loteprednol etabonate. 


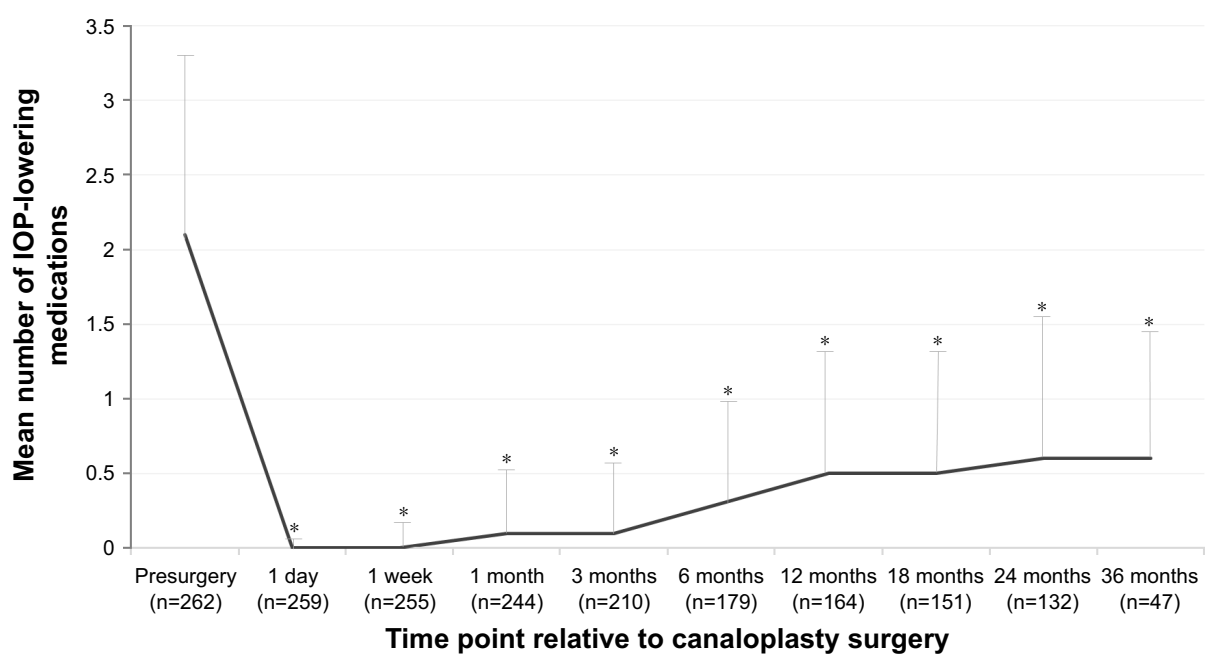

Figure 2 Intraocular pressure-lowering medication use following canaloplasty.

Notes: $* P<0.001$ vs baseline. $n$, number of subjects with evaluable data at each time point.

Abbreviation: IOP, intraocular pressure.

with IOP values $\leq 21 \mathrm{mmHg}$. Qualified success (use of $\leq 2$ IOP-lowering medications) at month 6 was noted in $90.6 \%$ of eyes with IOP values $\leq 21 \mathrm{mmHg}$. Surgical success at all subsequent time points through 36 months of follow-up generally paralleled these findings, though there appeared to be a slight reduction in eyes with complete success at longer follow-up intervals. At months 12, 24, and 36, complete success decreased from $67.3 \%$ to $66.1 \%$ to $63.4 \%$ of eyes with IOP values $\leq 21 \mathrm{mmHg}$, respectively. Additionally, the number of eyes with available data at each time point decreased.

\section{Safety outcomes}

As expected, most postsurgical complications occurred in the early postoperative period. Hyphema was the most frequently observed early postoperative complication, occurring in 126/259 (48.7\%), 39/255 (15.3\%), and $1 / 244(0.4 \%)$ of eyes at postoperative day 1 , week 1 , and month 3 , respectively. The majority of observed cases were classified as microhyphema $(54.5 \%$ of day 1 cases and $73.7 \%$ of week 1 cases), with a maximum severity recording of Grade II found in only three eyes at day 1. All cases of hyphema resolved spontaneously with no interventions required. Injection was noted in $\leq 4 \%$ of eyes at day 1 , week 1 , and months 1,3 , and 6 .

The proportion of subjects with categorically high or low IOP was recorded at each follow-up visit. A high IOP $(\geq 30 \mathrm{mmHg})$ was noted in 13/244 (5.3\%) eyes at week 1 , and rarely $(\leq 1.8 \%$ eyes) thereafter. IOP elevations did not lead to discontinuation of LE use. Instances of hypotony (IOP $<5 \mathrm{mmHg}$ ) occurred in 50/240 (20.8\%), 7/244 (2.9\%), 13/233 (5.6\%), and $5 / 201(2.5 \%)$ of eyes at postoperative day 1 , week 1 , month 1 , and month 3 , respectively, and in smaller percentages of eyes at subsequent visits. There was no intervention in cases of high or low IOP. Cataract formation was not noted in any of the phakic eyes during the follow-up period.

Table 4 Complete $^{\mathrm{a}}$ and qualified ${ }^{\mathrm{b}}$ surgical success rates (\%) at postoperative month 6, month I2, year 2, and year 3

\begin{tabular}{|c|c|c|c|c|c|}
\hline \multirow{2}{*}{$\begin{array}{l}\text { Success } \\
\text { category }\end{array}$} & \multicolumn{5}{|c|}{ Postoperative time point } \\
\hline & $\begin{array}{l}\text { Month } 6 \\
(n=170)\end{array}$ & $\begin{array}{l}\text { Month } 12 \\
(n=153)\end{array}$ & $\begin{array}{l}\text { Month 18 } \\
(n=139)\end{array}$ & $\begin{array}{l}\text { Month } 24 \\
(n=\mid 18)\end{array}$ & $\begin{array}{l}\text { Month } 36 \\
(n=4 I)\end{array}$ \\
\hline \multicolumn{6}{|c|}{ Complete success (\%) } \\
\hline$\leq 21 \mathrm{mmHg}$ & 78.8 & 67.3 & 62.6 & 66.1 & 63.4 \\
\hline$\leq 18 \mathrm{mmHg}$ & 69.4 & 62.8 & 59.0 & 60.2 & 61.0 \\
\hline$\leq 15 \mathrm{mmHg}$ & 51.2 & 47.7 & 45.3 & 48.3 & 53.7 \\
\hline \multicolumn{6}{|c|}{ Qualified success (\%) ${ }^{\mathrm{b}}$} \\
\hline$\leq 21 \mathrm{mmHg}$ & 90.6 & 95.4 & 92.8 & 92.4 & 92.7 \\
\hline$\leq 18 \mathrm{mmHg}$ & 78.2 & 84.3 & 81.3 & 84.8 & 82.9 \\
\hline$\leq 15 \mathrm{mmHg}$ & 56.5 & 62.1 & 59.7 & 69.5 & 70.7 \\
\hline
\end{tabular}

Notes: ${ }^{a}$ No use of IOP-lowering medication. bUse of $\leq 2$ (including 0 ) IOP-lowering medications. Abbreviation: IOP, intraocular pressure. 
There were no AE reports considered related to postoperative treatment with LE.

\section{Discussion}

These real-world findings in glaucoma patients who underwent canaloplasty with or without cataract surgery and were treated postoperatively with LE support the long-term safety and efficacy of this minimally invasive surgical procedure. It also corroborates a growing body of research on a variety of ocular surgery types supporting the clinical benefits and safety of LE formulations when used for control of inflammation during the postoperative period. ${ }^{47,48,56,66-68}$ While the gold standard for surgical management of glaucoma has traditionally been trabeculectomy, canaloplasty is increasingly being recognized as a much less invasive and maximally effective technique for achieving long-term IOP control. ${ }^{29}$

Canaloplasty lowers IOP by restoring the eye's natural trabeculocanalicular outflow system, thereby obviating the need for a subconjunctival filtering bleb, simplifying postoperative care, and reducing the likelihood of serious surgical complications inherent to trabeculectomy. ${ }^{15-21,30,31}$ Canaloplasty patients have also been found to experience a higher degree of satisfaction and less quality-of-life impairment after surgery when compared to trabeculectomy patients. ${ }^{25}$

In this observational study, mean IOP was reduced significantly from baseline and sustained over follow-up periods of up to 3 years along with significantly reduced use of adjunctive IOP-lowering medications. At 3 years of follow-up, about half of the eyes met the most stringent criteria for complete success, defined as an IOP $\leq 15 \mathrm{mmHg}$ and no concurrent use of IOP-lowering medications. About twothirds of eyes at 3 years of follow-up had IOP $\leq 21 \mathrm{mmHg}$ without concurrent IOP-lowering medication use. Although VA decreased during the first postoperative month relative to baseline, all subsequent measures were either similar or significantly improved compared to baseline.

Previous studies evaluating the efficacy of canaloplasty with 2-3 years of follow-up closely corroborate these findings, reporting mean IOPs of $13.1-17.0 \mathrm{mmHg}(34 \%-42.2 \%$ reductions from baseline), significant decreases in medication use, and complete (IOP $\leq 21 \mathrm{mmHg}$ without medications) and qualified (IOP $\leq 21 \mathrm{mmHg}$ with or without medications) success rates of $44.8 \%-77.5 \%$ and $81.6 \%-86.2 \%$, respectively. ${ }^{15-18,20,21,27}$ A recently reported canaloplasty study with 5 years of follow-up ${ }^{69}$ noted the need for additional surgery for IOP control in 13 of 20 (65\%) eyes at this time point, though the sample size was small. Ongoing collection of longer term data in larger studies will be needed to fully measure the long-term success of the procedure.
Despite the increasing literature on favorable outcomes with canaloplasty, there are no studies specific to pharmacologic management of these patients in the postoperative period. The typically recommended regimen of antibiotics coupled with a tapered dose of corticosteroids over 3-4 weeks ${ }^{29,34,66}$ is based on general guidelines for ocular surgery and does not account for the unique challenges of canaloplasty patients, who (unlike the trabeculectomy patient) continue to rely on the eye's natural outflow system to regulate IOP. ${ }^{29,34}$ Recent in vitro and in vivo studies suggest that eyes diagnosed with POAG have a smaller, less observable Schlemm's canal, decreased trabecular meshwork thickness, and increased trabecular meshwork stiffness when compared to healthy eyes, ${ }^{70-73}$ and, therefore, are more susceptible to IOP spikes. ${ }^{74,75}$ The canaloplasty procedure may illicit early postsurgical IOP spikes because of the eye's inflammatory response to surgery. This may impede aqueous humor passing into the collector channels in the immediate postoperative period. ${ }^{17,18,29,34}$ Similar findings of early postoperative IOP spikes have also been reported in glaucoma patients undergoing cataract surgery. ${ }^{76-78}$

While topical corticosteroids are important for the control of postoperative inflammation, their use in and of themselves can be associated with IOP elevations, especially in patients with a history of glaucoma. ${ }^{35,36,38,40}$ Corticosteroids can elevate IOP by causing a decrease in aqueous flow through the trabecular meshwork, the primary pathway for outflow. Possible mechanisms include increased extracellular matrix deposition, increased cross-linking of actin fibers between cells, and an inhibition of phagocytosis. ${ }^{38,40}$ Considering the aforementioned sensitivity of the canaloplasty patient to changes in the trabeculocanalicular outflow system following surgery, corticosteroid-induced IOP elevation has particular relevance in this setting.

In the author's practice, LE suspension or now the newer LE gel formulation is a standard part of postcanaloplasty surgery management. LE was developed using a retrometabolic design with the intention of lessening risks of IOP elevation and other unwanted effects of topical corticosteroid therapy. ${ }^{43}$ The chemical structure of LE is such that any drug that is not bound to the glucocorticoid receptor undergoes rapid conversion into inactive metabolites, allowing for localized, controlled suppression of ocular inflammation with minimized potential for causing unwanted side effects. ${ }^{41,42,44,45}$ Studies comparing LE suspension or gel to other corticosteroids, including dexamethasone, ${ }^{51,57,59-61}$ prednisolone, ${ }^{54-56,58,79,80}$ and flurometholone, ${ }^{50,81,82}$ have consistently found that LE has lower impact on IOP, while retaining the desired antiinflammatory effects of a corticosteroid. A recent review by 
Sheppard et al of the available published data on the effect of marketed LE formulations on IOP found that LE consistently demonstrated a low propensity to elevate IOP, regardless of the formulation, dosage regimen, or treatment duration, including in known steroid responders. ${ }^{53}$

In this real-world cohort of canaloplasty patients, postoperative management with LE suspension $0.5 \%$ appeared to be safe and effective. In accordance with numerous previous studies of LE suspension or LE gel following ocular surgery, ${ }^{47,48,56,66-68}$ postoperative inflammation was reduced as evidenced by AC cell and flare data with minimal clinically significant IOP elevations. In the current study, no AEs considered related to treatment with LE suspension were reported. The immediate and sustained decreases in IOP beginning 1 day after surgery and maintained over a period of up to 3 years likely reflect both the efficacy of the canaloplasty procedure as well as the low propensity of LE for inducing IOP elevations in the short term following the procedure. Early postoperative IOP spikes have been found in up to $20.3 \%$ of canaloplasty cases in the literature, ${ }^{31}$ though this complication is generally reported at lower rates even in the presence of postoperative topical corticosteroid use. ${ }^{16-20}$ However, differences in drug regimen and definition of an IOP spike confound comparisons across studies.

Other postoperative complications among patients in this review were mostly transient, required few interventions, and were typical for this type of surgical procedure. ${ }^{16,17,83}$ Hyphema was the most commonly observed and occurred in $48.7 \%$ of eyes at postoperative day 1 , with the majority of cases classified as microhyphema. Spontaneous resolution by month 3 was recorded for all eyes. Previous studies have reported similar findings of inconsequential hyphema in $6.1 \%-85.2 \%$ of canaloplasty cases, ${ }^{16-18,21}$ and one study ${ }^{84}$ concluded that the presence of microhyphema on the first postoperative day following canaloplasty might have positive prognostic value with regard to IOP reduction, as a reflux of blood may signify a patent trabecular meshwork. Hypotony, reported in $0.6 \%-27.6 \%$ of cases in the literature, ${ }^{16-18,21,30}$ was documented in $20.8 \%$ of eyes at day 1 in this retrospective review, and all cases resolved without intervention.

The main limitations of this study are those typical of retrospective chart review studies, including nonrandomization, which might lead to selection bias, incompleteness of chart data for outcomes of interest, and the lack of a control group. Furthermore, data gathering was limited primarily to objective findings, precluding evaluations of pain relief or patient satisfaction. A small number of eyes received a
non-LE steroid in the early postoperative period, and thus, these data were excluded from the analysis. However, it may be that these cases would have had less favorable outcomes if continued solely on LE. Given safety data were limited to information previously recorded during routine patient follow-up visits, minor complaints and less serious AEs may have been missed, though it is presumed that events of clinical significance would have been recorded.

\section{Conclusion}

Findings from this retrospective chart review point to the long-term safety and effectiveness of the canaloplasty procedure performed with or without cataract surgery and managed postoperatively with LE suspension $0.5 \%$. Complications related to the surgical procedure were mostly transient and comparable to those noted in previous canaloplasty studies. No adverse reactions considered related to LE were noted. Significant IOP reduction was achieved rapidly and sustained over a period of years with minimal need for adjunct medication use. Postoperative use of LE was associated with good control of postsurgical inflammation without apparent exacerbation of IOP. These data add to the increasing body of research supporting the clinical benefits and safety of LE $0.5 \%$ use during the postoperative period for a variety of ocular surgery types.

\section{Acknowledgments}

Writing assistance was provided by Rachel Hathcock, BSN, and Sandra Westra, PharmD, of Churchill Communications (Maplewood, NJ, USA) and was funded by Bausch + Lomb, Inc. The author retained full control over the manuscript content. This study was sponsored by Bausch + Lomb as an independent research grant.

\section{Author contributions}

MK substantially contributed to concept and design, data acquisition, and analysis and interpretation; he contributed to article drafting and revision and gave final approval of this version to be published; he is accountable for all aspects of the work and will ensure that questions related to the accuracy or integrity of the work are appropriately investigated and resolved.

\section{Disclosure}

The author reports no conflicts of interest in this work.

\section{References}

1. Heijl A, Leske MC, Bengtsson B, et al. Reduction of intraocular pressure and glaucoma progression: results from the Early Manifest Glaucoma Trial. Arch Ophthalmol. 2002;120(10):1268-1279. 
2. Kass MA, Heuer DK, Higginbotham EJ, et al. Ocular Hypertension Treatment study: a randomized trial determines that topical ocular hypotensive medication delays or prevents the onset of primary openangle glaucoma. Arch Ophthalmol. 2002;120(6):701-713.

3. Leske MC, Heijl A, Hussein M, et al. Factors for glaucoma progression and the effect of treatment: the early manifest glaucoma trial. Arch Ophthalmol. 2003;121(1):48-56.

4. The Advanced Glaucoma Intervention Study (AGIS): 7. The relationship between control of intraocular pressure and visual field deterioration. AGIS investigators. Am J Ophthalmol. 2000;130(4):429-440.

5. Lee PP, Walt JW, Rosenblatt LC, Siegartel LR, Stern LS, Glaucoma Care SG. Association between intraocular pressure variation and glaucoma progression: data from a United States chart review. Am J Ophthalmol. 2007;144(6):901-907.

6. Musch DC, Gillespie BW, Niziol LM, Lichter PR, Varma R, Cigts SG. Intraocular pressure control and long-term visual field loss in the collaborative initial glaucoma treatment study. Ophthalmology. 2011;118(9): 1766-1773.

7. Stewart WC, Kolker AE, Sharpe ED, et al. Factors associated with long-term progression or stability in primary open-angle glaucoma. Am J Ophthalmol. 2000;130:274-279.

8. Fingeret M, Mancil GL, Bailey IL, et al. Optometric Clinical Practice Guideline. Care of the Patient with Open Angle Glaucoma. St. Louis, MO: American Optometric Association; 2010. Available from: http://www.aoa.org/documents/optometrists/CPG-9.pdf. Accessed March 6, 2017

9. Prum BE, Rosenberg LF, Gedde SJ, et al. Primary open-angle glaucoma preferred practice pattern ${ }^{\circledR}$ guidelines. Ophthalmology. 2016;123(1) P41-P111.

10. Cairns JE. Trabeculectomy preliminary report of a new method. Am J Ophthalmol. 1968;66(4):673-679.

11. Razeghinejad MR, Fudemberg SJ, Spaeth GL. The changing conceptual basis of trabeculectomy: a review of past and current surgical techniques. Surv Ophthalmol. 2012;57(1):1-25.

12. DeBry PW, Perkins TW, Heatley G, Kaufman P, Brumback LC Incidence of late-onset bleb-related complications following trabeculectomy with mitomycin. Arch Ophthalmol. 2002;120(3):297-300.

13. Poulsen E, Allingham R. Characteristics and risk factors of infections after glaucoma filtering surgery. J Glaucoma. 2000;9(6):438-443.

14. Jampel H, Musch D, Gillespie B, Lichter P, Wright M, Guire K Perioperative complications of trabeculectomy in the collaborative initial glaucoma treatment study (CIGTS). Am J Ophthalmol. 2005; 140(1):16-22.

15. Matlach J, Dhillon C, Hain J, Schlunck G, Grehn F, Klink T. Trabeculectomy versus canaloplasty (TVC study) in the treatment of patients with open-angle glaucoma: a prospective randomized clinical trial. Acta Ophthalmol. 2015;93(8):753-761.

16. Bull H, von Wolff K, Körber N, Tetz M. Three-year canaloplasty outcomes for the treatment of open-angle glaucoma: European study results. Graefes Arch Clin Exp Ophthalmol. 2011;249(10):1537-1545.

17. Brusini P. Canaloplasty in open-angle glaucoma surgery: a four-year follow-up. ScientificWorldJournal. 2014;16:2014:469609.

18. Brusini P, Caramello G, Benedetti S, Tosoni C. Canaloplasty in openangle glaucoma: mid-term results from a multicenter study. J Glaucoma. 2014;25:403-407.

19. Gandolfi SA, Ungaro N, Ghirardini S, Tardini MG, Mora P. Comparison of surgical outcomes between canaloplasty and Schlemm's canal scaffold at 24 months' follow-up. J Ophthalmol. 2016;2016:3410469.

20. Grieshaber MC, Pienaar A, Olivier J, Stegmann R. Canaloplasty for primary open-angle glaucoma: long-term outcome. Br J Ophthalmol. 2010;94(11):1478-1482

21. Lewis RA, von Wolff K, Tetz M, et al. Canaloplasty: three-year results of circumferential viscodilation and tensioning of Schlemm canal using a microcatheter to treat open-angle glaucoma. J Cataract Refract Surg. 2011;37(4):682-690.

22. Rulli E, Biagioli E, Riva I, et al. Efficacy and safety of trabeculectomy vs. nonpenetrating surgical procedures: a systematic review and metaanalysis. JAMA Ophthalmol. 2013;131(12):1573-1582.
23. Lin Z, Xu S, Huang S, Zhang X, Zhong Y. Comparison of canaloplasty and trabeculectomy for open angle glaucoma: a meta-analysis. Int $J$ Ophthalmol. 2016;9(12):1814-1819.

24. Matlach J, Freiberg FJ, Leippi S, Grehn F, Klink T. Comparison of phacotrabeculectomy versus phacocanaloplasty in the treatment of patients with concomitant cataract and glaucoma. BMC Ophthalmol. 2013;13:1.

25. Klink T, Sauer J, Körber NJ, et al. Quality of life following glaucoma surgery: canaloplasty versus trabeculectomy. Clin Ophthalmol. 2015;9:7-16.

26. Schoenberg ED, Chaudhry AL, Chod R, Zurakowski D, Ayyala RS. Comparison of surgical outcomes between phacocanaloplasty and phacotrabeculectomy at 12 months' follow-up: a longitudinal cohort study. J Glaucoma. 2015;24(7):543-549.

27. Lewis RA, von Wolff $\mathrm{K}$, Tetz M, et al. Canaloplasty: circumferential viscodilation and tensioning of Schlemm's canal using a flexible microcatheter for the treatment of open-angle glaucoma in adults: interim clinical study analysis. J Cataract Refract Surg. 2007;33(7):1217-1226.

28. Shingleton B, Tetz M, Korber N. Circumferential viscodilation and tensioning of Schlemm canal (canaloplasty) with temporal clear corneal phacoemulsification cataract surgery for open-angle glaucoma and visually significant cataract: one-year results. $J$ Cataract Refract Surg. 2008;34(3):433-440.

29. Khaimi MA. Canaloplasty: a minimally invasive and maximally effective glaucoma treatment. J Ophthalmol. 2015;2015:485065.

30. Rekas M, Byszewska A, Petz K, Wierzbowska J, Jünemann A. Canaloplasty versus non-penetrating deep sclerectomy - a prospective, randomised study of the safety and efficacy of combined cataract and glaucoma surgery; 12-month follow-up. Graefes Arch Clin Exp Ophthalmol. 2015;253(4):591-599.

31. Arthur SN, Cantor LB, WuDunn D, et al. Efficacy, safety, and survival rates of IOP lowering effect of phacoemulsification alone or combined with canaloplasty in glaucoma patients. J Glaucoma. 2014; 23(5):316-320.

32. Ayyala RS, Chaudhry AL, Okogbaa CB, Zurakowski D. Comparison of surgical outcomes between canaloplasty and trabeculectomy at 12 months' follow-up. Ophthalmology. 2011;118(12):2427-2433.

33. Tetz M, Koerber N, Shingleton BJ, et al. Phacoemulsification and intraocular lens implantation before, during, or after canaloplasty in eyes with open-angle glaucoma: 3-year results. J Glaucoma. 2015; 24(3):187-194.

34. Cagini C, Peruzzi C, Fiore T, Spadea L, Lippera M, Lippera S. Canaloplasty: current value in the management of glaucoma. $J$ Ophthalmol. 2016;2016:7080475

35. McGhee CN, Dean S, Danesh-Meyer H. Locally administered ocular corticosteroids: benefits and risks. Drug Saf. 2002;25(1):33-55.

36. Clark AF, Wilson K, de Kater AW, Allingham RR, McCartney MD. Dexamethasone-induced ocular hypertension in perfusion-cultured human eyes. Invest Ophthalmol Vis Sci. 1995;36:478-489.

37. Rajpal RK, Digby D, D'Aversa G, Mah F, Hollander DA, Conway T. Intraocular pressure elevations with loteprednol etabonate: a retrospective chart review. J Ocul Pharmacol Ther. 2011;27(3):305-308.

38. Pleyer U, Ursell PG, Rama P. Intraocular pressure effects of common topical steroids for post-cataract inflammation: are they all the same? Ophthalmol Ther. 2013;2(2):55-72.

39. Yablonski ME, Burde RM, Kolker AE, Becker B. Cataracts induced by topical dexamethasone in diabetics. Arch Ophthalmol. 1978;96(3): 474-476.

40. Kersey JP, Broadway DC. Corticosteroid-induced glaucoma: a review of the literature. Eye. 2006;20(4):407-416.

41. Bhardwaj YR, Pareek A, Jain V, Kishore D. Chemical delivery systems and soft drugs: retrometabolic approaches of drug design Saudi Pharm J. 2014;22(4):290-302.

42. Hochhaus G, Chen L, Derendorf H, et al. Pharmacokinetic characterization and tissue distribution of the new glucocorticoid soft drug loteprednol etabonate in rats and dogs. J Pharm Sci. 1992;81(12):1210-1215.

43. Bodor N, Loftsson T, Wu WM. Metabolism, distribution, and transdermal permeation of a soft corticosteroid, loteprednol etabonate. Pharm Res. 1992;9(10):1275-1278. 
44. Druzgala P, Wu WM, Bodor N. Ocular absorption and distribution of loteprednol etabonate, a soft steroid, in rabbit eyes. Curr Eye Res. 1991;10(10):933-937.

45. Wu W, Huang F, Lee Y, Buchwald P, Bodor N. Pharmacokinetics of the sequential metabolites of loteprednol etabonate in rats. $J$ Pharm Pharmacol. 2008;60(3):291-297.

46. Howes J, Novack GD. Failure to detect systemic levels, and effects of loteprednol etabonate and its metabolite, PJ-91, following chronic ocular administration. J Ocul Pharmacol Ther. 1998;14(2):153-158.

47. Stewart R, Horwitz B, Howes J, Novack GD, Hart K. Double-masked, placebo-controlled evaluation of loteprednol etabonate $0.5 \%$ for postoperative inflammation. Loteprednol etabonate post-operative inflammation study group 1. J Cataract Refract Surg. 1998;24(11):1480-1489.

48. A double-masked, placebo-controlled evaluation of $0.5 \%$ loteprednol etabonate in the treatment of postoperative inflammation. The loteprednol etabonate postoperative inflammation study group 2 . Ophthalmology. 1998;105(9):1780-1786.

49. Zhang Q-S, Wang X, Wang Z-H, Zhang S-Z, Wang L, Xu W-X. Influence of topical Lotemax on intraocular pressure following excimer. Chin J Exp Ophthalmol. 2013;31(6):551-554.

50. Gao DH, Li KJ, Lu H. Clinical observations on the effect of Lotemax on changes in intra-ocular pressure after LASEK [sic: LASIK]. Int $J$ Ophthalmol. 2010;10(9):806-807.

51. Wu JS, Zhong XW, Zhang XX, Liu Q. A randomized controlled study on the application of $0.5 \%$ loteprednol etabonate eye drops after LASIK surgery. Chin J Exp Ophthalmol. 2012;30(7):641-645.

52. Mifflin MD, Leishman LL, Christiansen SM, Sikder S, Hsu M, Moshirfar M. Use of loteprednol for routine prophylaxis after photorefractive keratectomy. Clin Ophthalmol. 2012;6:653-659.

53. Sheppard JD, Comstock TL, Cavet ME. Impact of the topical ophthalmic corticosteroid loteprednol etabonate on intraocular pressure. Adv Ther. 2016;33(4):532-552.

54. Bartlett JD, Horwitz B, Laibovitz R, Howes JF. Intraocular pressure response to loteprednol etabonate in known steroid responders. J Ocul Pharmacol. 1993;9(2):157-165.

55. Holland EJ, Djalilian AR, Sanderson JP. Attenuation of ocular hypertension with the use of topical loteprednol etabonate $0.5 \%$ in steroid responders after corneal transplantation. Cornea. 2009;28(10): $1139-1143$

56. Lane SS, Holland EJ. Loteprednol etabonate $0.5 \%$ versus prednisolone acetate $1.0 \%$ for the treatment of inflammation after cataract surgery. J Cataract Refract Surg. 2013;39(2):168-173.

57. Thanathanee O, Sriphon $\mathrm{P}$, Anutarapongpan O, et al. A randomized controlled trial comparing dexamethasone with loteprednol etabonate on postoperative photorefractive keratectomy. J Ocular Pharmacol Ther. 2015;31(3):165-168.

58. Loteprednol Etabonate US Uveitis Study Group. Controlled evaluation of loteprednol etabonate and prednisolone acetate in the treatment of acute anterior uveitis. Am J Ophthalmol. 1999;127:537-544.

59. White EM, Macy JI, Bateman KM, Comstock TL. Comparison of the safety and efficacy of loteprednol etabonate $0.5 \%$ /tobramycin $0.3 \%$ with dexamethasone $0.1 \% /$ tobramycin $0.3 \%$ in the treatment of blepharokeratoconjunctivitis. Curr Med Res Opin. 2008;24:287-296.

60. Chen M, Gong L, Sun X, et al. A multicenter, randomized, parallelgroup, clinical trial comparing the safety and efficacy of loteprednol etabonate $0.5 \%$ /tobramycin $0.3 \%$ with dexamethasone $0.1 \%$ /tobramycin $0.3 \%$ in the treatment of Chinese patients with blepharokeratoconjunctivitis. Curr Med Res Opin. 2012;28:385-394.

61. Holland EJ, Bartlett JD, Paterno MR, Usner DW, Comstock TL. Effects of loteprednol/tobramycin versus dexamethasone/tobramycin on intraocular pressure in healthy volunteers. Cornea. 2008;27(1):50-55.

62. Wang Q, Harasymowycz P. Short-term intraocular pressure elevations after combined phacoemulsification and implantation of two trabecular micro-bypass stents: prednisolone versus loteprednol. J Ophthalmol. 2015;2015:341450.

63. Rebenitsch RL, Brown EN, Binder NR, et al. Effect of topical loteprednol on intraocular pressure after selective laser trabeculoplasty for open-angle glaucoma. Ophthalmol Ther. 2013;2(2):113-120.
64. International Conference on Harmonisation of technical requirements for registration of pharmaceuticals for human use. ICH harmonized tripartite guideline: guideline for good clinical practice. J Postgrad Med. 2001;47(1):45-50.

65. Khaimi MA. Canaloplasty using iTrack 250 microcatheter with suture tensioning on schlemm's canal. Middle East Afr J Ophthalmol. 2009;16(3): 127-129.

66. Rajpal RK, Roel L, Siou-Mermet R, Erb T. Efficacy and safety of loteprednol etabonate $0.5 \%$ gel in the treatment of ocular inflammation and pain after cataract surgery. J Cataract Refract Surg. 2013;39(2): $158-167$.

67. Comstock TL, Paterno MR, Singh A, Erb T, Davis E. Safety and efficacy of loteprednol etabonate ophthalmic ointment $0.5 \%$ for the treatment of inflammation and pain following cataract surgery. Clin Ophthalmol. 2011;5:177-186.

68. Fong R, Leitritz M, Siou-Mermet R, Erb T. Loteprednol etabonate gel $0.5 \%$ for postoperative pain and inflammation after cataract surgery: results of a multicenter trial. Clin Ophthalmol. 2012;6:1113-1124.

69. Voykov B, Blumenstock G, Leitritz M, Dimopoulos S, Alnahrawy O. Treatment efficacy and safety of canaloplasty for open-angle glaucoma after 5 years. Clin Exp Ophthalmol. 2015;43(8):768-771.

70. Yan X, Li M, Chen Z, Zhu Y, Song Y, Zhang H. Schlemm's canal and trabecular meshwork in eyes with primary open angle glaucoma: a comparative study using high-frequency ultrasound biomicroscopy. PLoS One. 2016;11(1):e0145824.

71. Hong J, Xu J, Wei A, et al. Spectral-domain optical coherence tomographic assessment of Schlemm's canal in Chinese subjects with primary open-angle glaucoma. Ophthalmology. 2013;120(4):709-715.

72. Hann CR, Vercnocke AJ, Bentley MD, Jorgensen SM, Fautsch MP. Anatomic changes in Schlemm's canal and collector channels in normal and primary open-angle glaucoma eyes using low and high perfusion pressures. Invest Ophthalmol Vis Sci. 2014;55(9):5834-5841

73. Huang J, Camras LJ, Yuan F. Mechanical analysis of rat trabecular meshwork. Soft Matter. 2015;11(14):2857-2865.

74. Stamer W. The cell and molecular biology of glaucoma: mechanisms in the conventional outflow pathway. Invest Ophthalmol Vis Sci. 2012; 53(5):2470-2472.

75. Brubaker R. Targeting outflow facility in glaucoma management. Surv Ophthalmol. 2003;48(Suppl 1):S17-S20.

76. Levkovitch-Verbin H, Habot-Wilner Z, Burla N, et al. Intraocular pressure elevation within the first 24 hours after cataract surgery in patients with glaucoma or exfoliation syndrome. Ophthalmology. 2008; 115(1):104-108.

77. Gupta A, Vernon SA. Is the 1-day postoperative IOP check needed post uncomplicated phacoemulsification in patients with glaucoma and ocular hypertension? Eye. 2015;29(10):1299-1307.

78. Chen PP, Lin SC, Junk AK, Radhakrishnan S, Singh K, Chen TC. The effect of phacoemulsification on intraocular pressure in glaucoma patients: a report by the American Academy of Ophthalmology. Ophthalmology. 2015;122(7):1294-1307.

79. Novack GD, Howes J, Crockett RS, Sherwood MB. Change in intraocular pressure during long-term use of loteprednol etabonate. J Glaucoma. 1998;7(4):266-269.

80. Price MO, Feng MT, Scanameo A, Price FW. Loteprednol etabonate $0.5 \%$ gel vs. prednisolone acetate $1 \%$ solution after descemet membrane endothelial keratoplasty: prospective randomized trial. Cornea. 2015; 34(8):853-858.

81. Li WT, Li H, Wei J. Clinical study on the application of $5 \mathrm{~g} / \mathrm{L}$ loteprenol etabonate ophthalmic suspension after LASIK. Int J Ophthalmol. 2010;10(9):1792-1793.

82. Coffey MJ, Decory HH, Lane SS. Development of a non-settling gel formulation of $0.5 \%$ loteprednol etabonate for anti-inflammatory use as an ophthalmic drop. Clin Ophthalmol. 2013;7:299-212.

83. Brandão LM, Grieshaber MC. Update on minimally invasive glaucoma surgery (MIGS) and new implants. J Ophthalmol. 2013;2013:705915.

84. Grieshaber MC, Schoetzau A, Flammer J, Orgül S. Postoperative microhyphema as a positive prognostic indicator in canaloplasty. Acta Ophthalmol. 2013;91(2):151-156. 
Clinical Ophthalmology

\section{Publish your work in this journal}

Clinical Ophthalmology is an international, peer-reviewed journal covering all subspecialties within ophthalmology. Key topics include: Optometry; Visual science; Pharmacology and drug therapy in eye diseases; Basic Sciences; Primary and Secondary eye care; Patien Safety and Quality of Care Improvements. This journal is indexed on

PubMed Central and CAS, and is the official journal of The Society of Clinical Ophthalmology (SCO). The manuscript management system is completely online and includes a very quick and fair peer-review system, which is all easy to use. Visit http://www.dovepress.com/ testimonials.php to read real quotes from published authors. 